\title{
Object distance scaling in real space is preserved in low vision subjects
}

\author{
Fabrizzio Petroni Cecchele ${ }^{1,3}$, Márcia Caires Bestilleiro Lopes ${ }^{1,3}$, Célia Regina Nakanami ${ }^{3}$ and Marcelo Fernandes Costa ${ }^{1,2^{*}}$ \\ *Correspondence: costamf@usp.br \\ 'Núcleo de Neurociências e Comportamento e Neurociências Aplicada, Universidade de São Paulo, São Paulo, Brasil. \\ ${ }^{2}$ Departamento de Psicologia Experimental do Instituto de Psicologia da Universidade de São Paulo, São Paulo, Brasil. \\ ${ }^{3}$ Setor de Estimulação Visual Precoce do Departamento de Oftalmologia da Universidade Federal de São Paulo, São Paulo, Brasil.
}

\begin{abstract}
Purpose: We investigate the ability of adults with and without visual impairment estimate distances between stimuli in real environment. Methods: $\mathrm{W}=\mathrm{e}$ evaluated 12 subjects aged between 20 and 40 years in which 6 subjects with normal vision (mean age $=31.0, \mathrm{SD}=6.5$ ), and 6 subjects with visual impairment (mean age $=27.7, \mathrm{SD}=7.8$ ). Two styrofoam balls of $10 \mathrm{~cm}$ in diameter were used, painted in black and a line of white velcro of 3.5 meters was fixed in the floor of a hallway without lateral references. Psychophysical scaling was evaluated by magnitude estimation and the exponent of the Stevens' law was calculated.

Results: The calculated exponent for the controls was 1.13 for near judgment and 1.11 for far distances. The low vision group showed exponent values of 1.01 for near and 0.96 for far distances judgment. There was a statistical difference for $120 \mathrm{~cm}$ of distance between balls for near $\left(\mathrm{F}_{10}=88.21, \mathrm{p}<0.001\right)$ and a tendency to difference for $200 \mathrm{~cm}\left(\mathrm{~F}_{10}=3.81, \mathrm{p}=0.079\right)$ between groups.

Conclusions: Our scaling procedure shows that despite the reduction in the distance judged by the low vision subjects, their internal representation of space is preserved. Similar exponent values indicates that their suprathreshold impression of the distance follow the same rules of the normal subject.
\end{abstract}

Keywords: Distance perception, visual impairment, real distance judgment, magnitude estimation, perceptual rehabilitation, clinical psychophysics

\section{Introduction}

Our vision is guided by the egocentric references in which we have a better accuracy in distance judgment than for exocentric vision [1]. Although our locomotion in space is based on the ability to estimate distances between objects in our visual space, few studies directly address this issue. Thus they also used the measurement of stereoscopic depth perception that is not closely related with long distances judgments [2-5]. The effectiveness of egocentric distance estimation improves due to the binocular disparity using the angle of convergence of the two eyes over distances of two to six meters $[6,7]$. Constant feedbacks of small displacements of the retina image are using to continually, adjust the distance between things when we move in space. $[7,8]$.

Surfaces are also important cues in judging distances. Subjects can estimate surface properties using measurements such as textures, the average brightness, and contrast between light and shadow parts of the image [9].

In our daily life, the perceived size of objects plays an important role in helping people to move in the natural environment through ongoing evaluation of the sizes of objects and spaces [10]. When an object is presented in a visual angle of about $2^{\circ}$ or less we tend to overestimate the size of objects at angles greater than $2^{\circ}$ we have a slight tendency to underestimate the size. According to those authors, subjects with low vision have increased wrong judgments on the estimated size than people with normal vision. The chromaticity is a factor that also affects the estimated sizes, in which the more saturated the color, the closer it seems while more neutral colors seem more distant [10].

Another interesting point related to our topic is the fact of our perceptual distances is not linearly related to the physical (objective) distances. So, the space judgment during mobility is a learning function [11]. In this line, other studies report that the error in our spatial judgments increase as the distance increases [12-14].

Considering distance judgment in subjects with visual impairment, even fewer studies were performed. Correlation between a self-report questionnaires regarding spatial location suggest that some subjects with visual impairment have difficulty with real-world spatial tasks [15]. These difficulties could be predicted by their Vernier acuity results. Another important study is the one of Leat and Lovie-Kitchin [16]. These authors measured visual acuity, contrast sensitivity and visual field attention and compared then with the real-life mobility quality. Their results shown a low to moderate correlation $(r=0.38)$ between mobility performance and contrast sensitivity. The authors concluded that attention and the presence of distractors are important factors in mobility performance.

Thus, the purpose of this study is to investigate how adults subjects 
with and without visual impairment estimate spatial distances between simple stimuli on a real environment, addressing the ego-exocentric judgments in searching of possible impacts of visual impairment in that spatial function.

\section{Materials and methods Subjects}

We evaluated 12 adult subjects aged between 20 and 40 years in which 6 subjects with normal vision (mean age=31.0, SD=6.5), and 6 subjects with visual impairment (mean age $=27.7, \mathrm{SD}=$ 7.8). Exclusion criteria were systemic pathologies associated with the visual impairment and the using of central nervous system effect drugs. Demographic data are presented in (Table 1).

Table 1. Demographic data of the Control and Low Vision Subjects.

\begin{tabular}{|c|c|c|c|c|c|}
\hline ID & Age & Gender & VA OD & VA OS & $\begin{array}{l}\text { Ophthamological } \\
\text { Diagnosis }\end{array}$ \\
\hline \multicolumn{6}{|c|}{ Controls } \\
\hline 1 & 32 & F & $20 / 20$ & $20 / 20$ & Normal \\
\hline 2 & 38 & F & $20 / 20$ & $20 / 20$ & Normal \\
\hline 3 & 23 & M & $20 / 20$ & $20 / 20$ & Normal \\
\hline 4 & 32 & F & $20 / 20$ & $20 / 20$ & Normal \\
\hline 5 & 29 & M & $20 / 20$ & $20 / 20$ & Normal \\
\hline 6 & 25 & $\mathrm{~F}$ & $20 / 20$ & $20 / 20$ & Normal \\
\hline \multicolumn{6}{|c|}{ Low Vision } \\
\hline 1 & 23 & M & $20 / 160$ & $20 / 200$ & $\begin{array}{l}\text { High myopia and } \\
\text { congenital strabismus }\end{array}$ \\
\hline 2 & 29 & $\mathrm{~F}$ & $20 / 150$ & $20 / 80$ & $\begin{array}{l}\text { Congenital } \\
\text { nistagmus, glaucoma } \\
\text { and cataracts }\end{array}$ \\
\hline 3 & 33 & F & $20 / 160$ & $20 / 150$ & $\begin{array}{l}\text { Binocular macular scar } \\
\text { by toxoplasmosis }\end{array}$ \\
\hline 4 & 30 & F & $20 / 200$ & $20 / 150$ & $\begin{array}{l}\text { Binocular macular scar } \\
\text { by toxoplasmosis }\end{array}$ \\
\hline 5 & 25 & M & $20 / 200$ & $20 / 120$ & $\begin{array}{l}\text { Binocular } \\
\text { congenital glauoma }\end{array}$ \\
\hline 6 & 32 & F & $20 / 120$ & $20 / 200$ & $\begin{array}{l}\text { Congenital binocular } \\
\text { cataracts }\end{array}$ \\
\hline
\end{tabular}

The experiment was performed at the Department of Low Vision and Visual Rehabilitation of Federal University of São Paulo (UNIFESP), Brazil.

This is a cross and experimental study and was carried out in the period from June to October after the approval of the Ethics and Research of UNIFESP (\#04.023-061), and follows the principles of the Declaration of Helsinki. All subjects signed the consent form.

\section{Materials and procedure}

Two styrofoam balls of $10 \mathrm{~cm}$ in diameter each, painted in black, were the stimuli used to calculate the distance judgment. A line of white velcro (3M Dual Lock Reclosable Fasteners, St. Paul, MN, USA) of 3.5 meters that was fixed in the floor of a hallway without lateral references was used to fixate the balls.

These balls were fixed on the velcro (velvet) in such manner that one ball was positioned in front of the other. The distances between the balls varied in $10 \mathrm{~cm}$ steps considering two experimental conditions: 1 . for exocentric judgment of distances-a reference ball was fixed at 1 meter from the subjects while the other ball varied; 2 . for egocentric judgment of distances-the reference ball remains fixed at 3 meters from the subject while the target ball varied. The position of the target ball was randomly chosen between $30 \mathrm{~cm}$ to $200 \mathrm{~cm}$ from the reference ball.

Each participant was instructed by the researcher about the procedure and guidelines of the experiment, but was not informed about the white velcro line length and no information was gave about the step size of the distances. Subjects were positioned on a yellow line reference on the front line of velcro.

Participants had their eyes closed in those moments when the ball was changing in distance. The task consisted of as soon as (s)he opened their eyes, they have to look at the ball and immediately judge the estimated distance.

Since we are using a ratio procedure, subjective scaling was evaluated by the magnitude estimation procedure and the exponent of the Stevens' Power Law was calculated according to the following equation:

$$
\mathrm{S}=\mathrm{k} \mathrm{I}^{\mathrm{n}} \quad \text { (equation 1) }
$$

where, $\mathrm{S}$ is the judged (subjective) magnitude, $\mathrm{k}$ is a constant regarding to the condition, I is the physical intensity - in our case, the spatial distance between the balls and $\mathrm{n}$ is the exponent that characterizes those relations.

\section{Statistical analysis}

A full descriptive statistical analysis was performed using the Statistica (Statsoft v12, Tulsa, USA). Comparison between the groups was performed using One-Way ANOVA considering group and distance. Differences were calculated by Tukey post hoc test. Paired Student T-test was used to compute differences within groups. Wilk's lambda that measures the unique contribution of a respective variable to the discrimination between groups was also calculated.

\section{Results}

The distances were successfully obtained for all subjects of both groups. The control group showed an exponent of 1.13 (with a Pearson correlation coefficient of $r=0.992$ ) for the exocentric judgment and an exponent of $1.11(r=0.996)$ for the egocentric judgment of distance. Similarly, the low vision group had an exponent of 1.01 ( $r=0.991)$ for the exocentric judgment and an exponent of $0.96(r=0.984)$ for the egocentric judgment (Figure 1).

The difference found between the controls and the low vision subjects for exocentric (0.12) and for egocentric judgments 

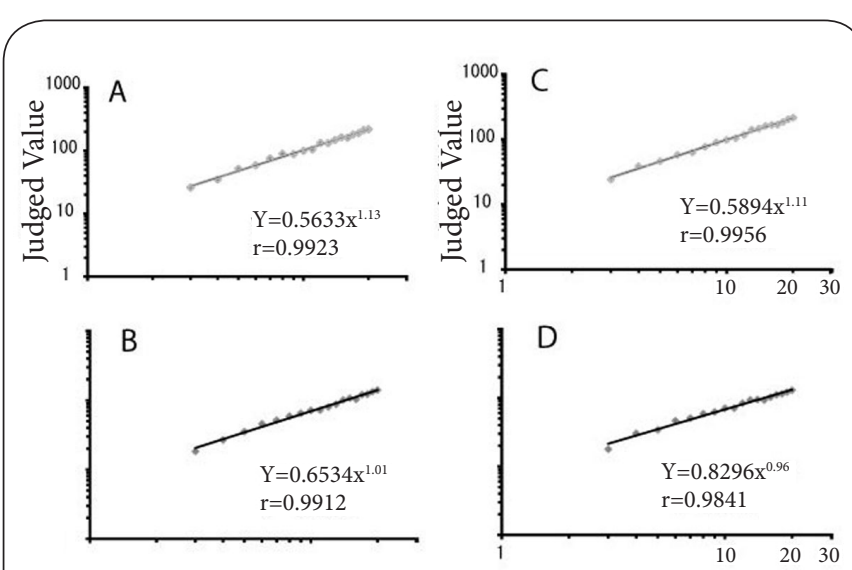

Physical Value

Fiuge 1. Stevens' exponent measurements of the real object distance judgments obtained for the control (A-C) and low vision subjects (B-D). The superior graphics represent the judgment to egocentric stimuli and the inferior graphics the judgment to exocemtric stimuli. Exponent values more than 1.0 means an expansive judgment and exponent less then 1.0 indicates a compression perception. The high correlation coefficient is resulted by the high accordance in the subjects judgment.

(0.15) suggest a compressive perceptual distortion in distance judgments, respectively, of 3.2 and 4.1 times for low vision subjects.

Comparing the amplitude of the subjective estimation performed by the low vision group with the control group, there was a statistical difference for $120 \mathrm{~cm}$ of distance between balls $\left(\mathrm{F}_{10}=88.21, \mathrm{p}<0.001\right)$ and a tendency to difference for $200 \mathrm{~cm}\left(\mathrm{~F}_{10}=3.81, \mathrm{p}=0.079\right)$ for egocentric judgments (Figure 2). The Wilk's lambda measured for $120 \mathrm{~cm}$ was W=0.06 (Chi-Sqr $=18.38 ; p=0.004$ ) which had a corrected difference between groups of $F=29.63 ; p=0.002$. No difference was found for $40 \mathrm{~cm}$ for egocentric and for all 40, 120 and $200 \mathrm{~cm}$ for exocentric judgments.

We also compared the distances judgment to egocentric and exocentric conditions within groups. Controls showed similar subjective estimations for both conditions. Low vision subjects had similar subjective estimations to egocentric $(40 \mathrm{~cm})$ and exocentric $(200 \mathrm{~cm})$ conditions, with a statistical worse judgment for egocentric compared to exocentric conditions at middle distance-120cm ( $T=-3.97, p=0.011)$.

\section{Discussion}

We found very impressive and meaningful results showing impairment in distance judgment in a small group of low vision adults. The first main result was a measurable reduction of the exponent of the Stevens' law judgment $[17,18]$ in the low vision subjects, meaning an underestimation of the perceived distances between the reference and the target ball. This is a new interesting finding since the spatial distance judgment was different comparing with normal subjects.

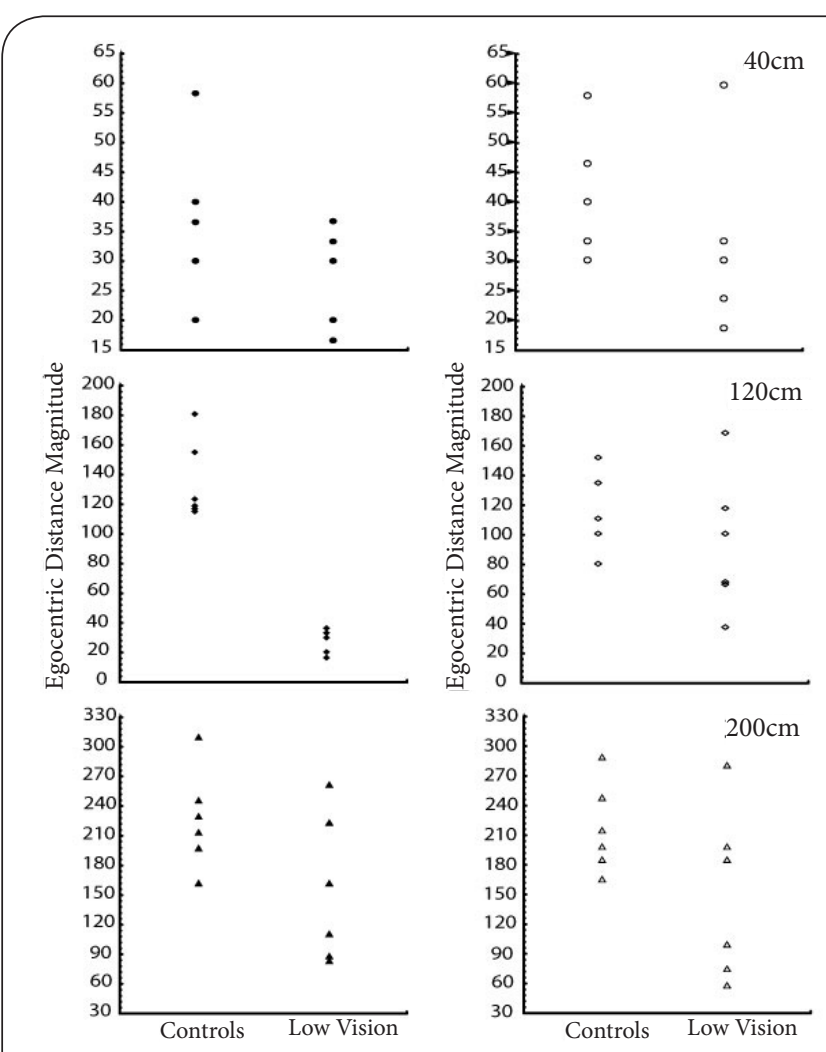

Figures 2. Real distance judged by controls and low vision subjects indicating a significant difference distance perceived between the two groups. Higher judgments differences were obtained for egocentric conditions.

When we look to the values judged by the low vision subject there was a significant distortion in their perception. However, the small reduction in the exponent of the psychophysical scaling strongly suggests that their internal representation of space is preserved. The similar exponent values indicates that their suprathreshold impression of the distance follow the same perceptual rules than the normal subject. Fundamentally, this is extremely relevant information about the perceptual construction in visual impairment subjects. Even with the reduction in their function for visual discrimination of spatial elements measured by visual acuity their perceptual organization of space was not proportionally affected by the disturbed input.

The second main result came from the comparison of perceived distances considering the distance from the subject of the reference ball. We aiming explore if those different distances of the reference could be related with possible differences in perceived distance of the target ball. Our results showed a significant reduction in distance judgment for the low vision group for middle distances $-120 \mathrm{~cm}$-and only for the egocentric condition. No differences were found for very near or for distant conditions and for all the exocentric judgment. Considering these two results we argue that subjects with low vision had impairment in distance judgment reducing their subjective perception in comparison with normal subjects 
Cecchele et al. Journal of Integrative Psychology and Therapeutics 2014, http://www.hoajonline.com/journals/pdf/2054-4723-2-1.pdf

and it could be reflecting some developmental damages due to the visual disability. A similar result was obtained in a study evaluating the self-reported difficulties experienced by visually impaired subjects in real-world tasks requiring distance judgments [15]. A spatial localization questioner was applied by those authors to visual impairment subjects and their result suggests that subjects with visual impairment had difficulties in distance judgment and it was correlated with the Vernier acuity. Our results showing differences in distance perception are in line with that study since both found impairments in hyperacuities (Vernier and distance judgment).

Clinical relevance of our results could be though in means of rehabilitation programs. All of those previous studies failed in correlate mobility performance with basic visual functions as visual acuity or spatial contrast sensitivity for luminance $[15,16]$. Based in our findings we suggest that the clinical measurements should include more perceptual (high level) functions as contour integration and real distance perception than those classical visual tasks as visual acuity and contrast sensitivity.

Our data also shows that the egocentric judgment was more impaired than the exocentric judgments which are also in line with the developmental damages of visual impairment. According to some studies, many different functions exhibit ego-exocentric asymmetry. Both visual perception of elevation and verticality show a strong egocentric bias [19]. Similar bias to egocentric judgments have been reported in spatially distributed targets [20] and for large field distances measurements [21].

New insights about the distance perception could be obtained from our data. Although there were differences in the distance judged by low vision subjects the similar exponent measured by power law means that they lost the visual ability to quantify precisely the distance between themselves and the objects but they maintain the internal magnitude for those perceived distances.

Low vision could be affecting more intermediary distances since we were not able to find differences in near and far distances to egocentric judgment. For near distances, additional cues could be helping the distance between features in the ambient. For far distances, our ability to judge is normally impaired and the visual impairment could not be so relevant. Additionally, we found a tendency to a deficit in judgment for far distances to egocentric judgment. The number of subjects in our study not allows us to considerate that tendency supportive.

In both groups subjects had a trend to underestimate the far distances and overestimate the near distances between the two balls. The group of normal vision was more accurate than the group with low vision, however, the estimation were not accurate. Sharrack et al., [22] shown that even doctors and patients of a hospital are fairly imprecise to estimate distance between spaces in the hospital. In our study, we observed that for small distances between the two balls there was an expansion judgment in the estimations and for large distances there was the oppose effect, a compression.

Analyzing what we named "internal coherence" for control and low-vision patient judgments, we found a similar result even in those cases that the estimations magnitudes showed quantifiable imprecisions. Contrary results were found by Lappe et al., [23] in which subjects were asked to estimate the distance traveled in a virtual environment. In that study, the subjects were sat inside a cube which was designed at the front an image of a virtual corridor and they had to press a button when they felt that the distance perceived was agree with the criteria distance. Dynamic events also do not help subjects to improve their distance judgment. Subjects in a virtual environment performing a walk task showed that the perception of walked distances were not correlated with their previously distance judged [24]. These authors also found an underestimation of distance to egocentric judgment, a result that is in line with ours.

\section{Conclusion}

Visually impaired subjects have more difficulty in quantify distances comparing to subjects with normal vision. In real life conditions, those distortions in distance estimation could generate accidents during their daily activities as walking between furniture and other obstacles. We also found that despite their low visual function, the "internal coherence" regarding the spatial environment was not significantly affected. This is a valuable information since it suggests that the perceptual organization of space is preserved even if based on a different (quantity of) visual input. Rehabilitation programs for subjects with low vision must take into account this "internal coherence" of spatial relationships, suggesting that the mobility and locomotion training should be focused on this property preserved visual perception. Our hypothesis is that since the subject can learn to correct the quantifiable perceived distances, internal coherence preserved must accompany this change, making the rehabilitation process more effective.

\section{Competing interests}

The authors declare that they have no competing interests.

\section{Authors' contributions}

\begin{tabular}{|l|c|c|c|c|}
\hline Authors' contributions & FPC & MCBL & CRN & MFC \\
\hline Research concept and design & $\checkmark$ & $\checkmark$ & $\checkmark$ & $\checkmark$ \\
\hline Collection and/or assembly of data & $\checkmark$ & $\checkmark$ & -- & -- \\
\hline Data analysis and interpretation & $\checkmark$ & $\checkmark$ & $\checkmark$ & $\checkmark$ \\
\hline Writing the article & $\checkmark$ & -- & -- & -- \\
\hline Critical revision of the article & $\checkmark$ & -- & -- & $\checkmark$ \\
\hline Final approval of article & $\checkmark$ & $\checkmark$ & $\checkmark$ & $\checkmark$ \\
\hline Statistical analysis & $\checkmark$ & -- & -- & $\checkmark$ \\
\hline
\end{tabular}

\section{Acknowledgement}

The authors would like to thank the main staff of the Low Vision and Visual Rehabilitation Section of the Federal University of São Paulo for all the logistic support, FAPESP-Auxílio à Pesquisa 
(Processo \#2013/04049-4) and CNPq Edital Universal (Edital MCT/ CNPq 14/2010 - Universal \# 472093/2010-0). MFC is a CNPq Fellow researcher level 2 .

\section{Publication history}

Editor: Donald M. Dougherty, University of Texas Health Science Center at San Antonio, USA.

Received: 18-Oct-2013 Revised: 05-Dec-2013

Accepted: 12-Jan-2014 Published:

\section{References}

1. Loomis JM, Da Silva JA, Fujita N and Fukusima SS. Visual space perception and visually directed action. J Exp Psychol Hum Percept Perform. 1992; 18:906-21. | Article | PubMed

2. Allison RS, Gillam BJ and Palmisano SA. Stereoscopic discrimination of the layout of ground surfaces. J Vis. 2009; 9:8 1-11. | Article | PubMed

3. Lappe $\mathrm{M}$ and Frenz $\mathrm{H}$. Visual estimation of travel distance during walking. Exp Brain Res. 2009; 199:369-75. | Article | PubMed

4. Norman JF, Todd JT, Perotti VJ and Tittle JS. The visual perception of three-dimensional length. J Exp Psychol Hum Percept Perform. 1996; 22:173-86. | Article | PubMed

5. Palmisano S, Gillam B, Govan DG, Allison RS and Harris JM. Stereoscopic perception of real depths at large distances. J Vis. 2010; 10:19. | Article | PubMed

6. Wu J, He ZJ and Ooi TL. Perceived relative distance on the ground affected by the selection of depth information. Percept Psychophys. 2008; 70:707-13. | Article | PubMed

7. Plooy A, Tresilian JR, Mon-Williams M and Wann JP. The contribution of vision and proprioception to judgements of finger proximity. Exp Brain Res. 1998; 118:415-20. | Article | PubMed

8. Lourenco SF and Longo MR. General magnitude representation in human infants. Psychol Sci. 2010; 21:873-81. | Article | PubMed Abstract I PubMed Full Text

9. Ho CS and Giaschi DE. Deficient maximum motion displacement in amblyopia. Vision Res. 2006; 46:4595-603. | Article | PubMed

10. Huang KC, Wang HF and Chen CC. Effects of shape, size, and chromaticity of stimuli on estimated size in normally sighted, severely myopic, and visually impaired students. Percept Mot Skills. 2010; 110:931-40. I PubMed

11. Felippe JAM and Felippe VLR. Orientação e mobilidade. Laramara, 1997.

12. Da Silva JA. Scales for measuring subjective distance in children and adults in a large open field. J Psychol. 1983; 113:221-30. | Article | PubMed

13. da Silva JA. Ratio estimation of distance in a large open field. Scand J Psychol. 1983; 24:343-5. | Article | PubMed

14. Da Silva JA, Matsushima EH, Aznar-Casanova JA and Ribeiro-Filho NP. Distance perception in a natural outdoor setting: is there a developmental trend to overconstancy? Span J Psychol. 2006; 9:285-94. | Pdf | PubMed

15. Subramanian A and Dickinson C. Spatial localization in visual impairment. Invest Ophthalmol Vis Sci. 2006; 47:78-85. | Article | PubMed

16. Leat SJ and Lovie-Kitchin JE. Visual function, visual attention, and mobility performance in low vision. Optom Vis Sci. 2008; 85:1049-56. Article I PubMed

17. Stevens SS. The direct estimation of sensory magnitudes-loudness. Am J Psychol. 1956; 69:1-25. | Article | PubMed

18. Stevens SS. Cross-modality validation of subjective scales for loudness, vibration, and electric shock. J Exp Psychol. 1959; 57:201-9. | Article | PubMed

19. Shavit AY, Li W and Matin L. Individual differences in perceived elevation and verticality: evidence of a common visual process. Multisens Res. 2013; 26:205-39. | Article | PubMed
20. Jiang YV, Swallow KM and Sun L. Egocentric coding of space for incidentally learned attention: Effects of scene context and task instructions. J Exp Psychol Learn Mem Cogn. 2014; 40:233-50. | Article | PubMed

21. Daum SO and Hecht H. Distance estimation in vista space. Atten Percept Psychophys. 2009; 71:1127-37. I Article I PubMed

22. Sharrack $B$ and Hughes RA. Reliability of distance estimation by doctors and patients: cross sectional study. BMJ. 1997; 315:1652-4. | Article | PubMed Abstract | PubMed Full Text

23. Lappe $M$ and Frenz $\mathrm{H}$. Visual estimation of travel distance during walking. Exp Brain Res. 2009; 199:369-75. | Article | PubMed

24. Kelly JW, Donaldson LS, Sjolund LA and Freiberg JB. More than just perception-action recalibration: walking through a virtual environment causes rescaling of perceived space. Atten Percept Psychophys. 2013; 75:1473-85. | Article | PubMed

Citation:

Cecchele FP, Lopes MCB, Nakanami CR and Costa MF. Object distance scaling in real space is preserved in low vision subjects. J Integr

Psychol Ther. 2014; 2:1.

http://dx.doi.org/10.7243/2054-4723-2-1 